\title{
Survey of Seafloor at Chagwi-do of Jeju Island to Select 60-m-class Sea Test Bed of Wave Energy Converter
}

\author{
Hansoo Kim*, Jeongrok Kim*, Il-Hyoung Cho*, Dong-Guk Paeng ${ }^{*}$ and Jong-Su Choi ${ }^{* * *}$ \\ *Department of Ocean System Engineering, Jeju National University, Jeju, Korea \\ ${ }^{* *}$ Maritime security research center, Korea Institute of Ocean Science E Technology, Ansan, Korea \\ ${ }^{* * *}$ Offshore Plant Research Division, Korea Research Institute of Ships E Ocean Engineering, Daejeon, Korea
}

\author{
$60 \mathrm{~m}$ 급 파력발전 실해역 시험장 선정을 위한 \\ 제주도 차귀도 해역의 해저 지층 탐사 \\ 김한수 ${ }^{* *}$ 김정록 ${ }^{*}$ 조일형* $\cdot$ 팽동국 ${ }^{*}$ 최종수 ${ }^{* *}$ \\ "제주대학교 해양시스템공학과 \\ "한국해양과학기술원 해양방위연구센터 \\ * 한국해양과학기술원 부설 선박해양플랜트연구소, 해양플랜트연구부
}

KEY WORDS: Sea test-bed 실해역 시험장, Suction anchor 석션 앵커, Sediment 퇴적물, Sub-bottom profiler 천부지층탐사기, Survey of sea floor 해저 지층 탐사

\begin{abstract}
The purpose of this study was to investigate the sea floor using a seismic profiler in the northern part of Chagwi-do of Jeju Island in order to select the optimal location for the 60-m-class berth of a sea test bed for wave energy converters and provide basic environmental data for designing a suction anchor. The echo types of the seismic profiles were classified based on the study of Kim et al. (2016a), and the location for installing the suction anchor was selected based on a sediment thickness of more than $10 \mathrm{~m}$. The physical properties of the surface sediments were determined by analyzing the sediment samples obtained from 16 grab sample points. Based on the investigation and analysis, we proposed a survey area in the North-Eastern sea as an optimum location for the 60-m-class berth where the suction anchor could be installed.
\end{abstract}

\section{1. 서 론}

최근에 해양 신재생에너지 보급 확대 및 국내 관련 산업 육성 을 위한 방안으로 파력발전 실해역 시험장 구축을 추진하고 있 다(Kim et al., 2016b). 파력발전 실해역 시험장은 수심 별로 다수 의 정박지(Berth)를 갖추고 있으며, 고객이 주문대로 설계 제작 된 파력발전 장치를 시험장에 설치, 유지/보수, 성능 평가, 철거 까지 실증 실험에 필요한 모든 것을 제공해 준다. 바다를 이용 함에 있어 필요한 정책적, 제도적 문제가 발생하지 않기 때문에 고객의 입장에서는 이에 관련된 번거로움을 피할 수 있어 실증 실험에 필요한 기간을 크게 단축시킬 수 있다. 국가적 차원에서 파력발전 장치 개발을 유도할 수 있으며, 한 곳에서 실증 실험 을 수행하기 때문에 중복 투자를 크게 줄일 수 있는 효과가 있 다. 제주도 차귀도 주변 해역은 파랑에너지 밀도가 높고, 해상
교통량이 적으며, 인근에 한림항과 애월항과 같은 중형 항구를 갖추고 있다. 또한 신재생 에너지로 도내 전력의 $100 \%$ 를 충당하 기를 원하는 제주도의 에너지 정책을 고려해 볼 때 차귀도 해역 은 파력발전 실해역 시험장의 최적지로 여겨진다.

부유식 파력발전 장치는 환경 외력 하에서 설치 위치를 유지하 기 위하여 앵커 또는 계류 시스템이 필요하며, 수심, 해저 지형, 해저 지층 등이 앵커 시스템 설계에 반영된다. 현재 고려중인 수 심 $15 \mathrm{~m}, 40 \mathrm{~m}, 60 \mathrm{~m}$ 정박지 중에서 수심 $60 \mathrm{~m}$ 급 정박지는 외해로 나가야 하므로 해저 케이블 설치비용이 절감될 수 있도록 가능한 한 해상 변전 시설과 가깝게 위치해야 한다. $60 \mathrm{~m}$ 급 정박지에 사 용될 앵커 유형은 상대적으로 설치비용이 저렴하고 안정성이 높 은 석션 앵커(Suction anchor)를 고려하고 있다. 석션 앵커는 내· 외부의 압력차를 이용하여 앵커를 해저로 관입하는 장치로 해상 에서의 설치가 용이하고, 크기 및 설치 수심에 크게 제약을 받지

Received 13 March 2017, revised 14 March 2017, accepted 4 August 2017

Corresponding author Il-Hyoung Cho: +82-10-9232-1253, cho0904@jejunu.ac.kr

(C) 2017, The Korean Society of Ocean Engineers

This is an open access article distributed under the terms of the creative commons attribution non-commercial license (http://creativecommons.org/licenses/by-nc/3.0) which permits unrestricted non-commercial use, distribution, and reproduction in any medium, provided the original work is properly cited. 
않기 때문에 심해의 석유시추선과 같은 해양 부유구조물의 앵커 시스템에 널리 활용되고 있다(Kim et al., 2005a, Kim et al., 2005b). 그러나 해저면 관입이 불가능한 암반지대인 경우 석션 앵커를 사용할 수 없다. 따라서 수심 $60 \mathrm{~m}$ 급 정박지를 선정하기 위해서 다음과 같은 조건을 만족하도록 하였다. (1) 수심 $50 \sim 70 \mathrm{~m}$ 이내에 위치하여야 하며, (2) 해저 케이블 설치비용 절감을 위하 여 해상변전시설과 가까운 거리에 위치하여야 하며, (3) 해저 지 층이 석션 앵커의 관입이 가능한 퇴적층(사질 또는 니질)으로 이 루어져있고, 깊이는 최소 $10 \mathrm{~m}$ 이상을 확보해야하며, (4) 해저 지 형은 평탄하면서 동시에 다점 현수선(Catenary) 계류 설치를 위해 비교적 넓은 지역(반경 $500 \mathrm{~m}$ 이상)을 확보해야 한다. 이상의 4 가 지 조건을 만족하는 수심 $60 \mathrm{~m}$ 급 정박지 해역을 찾기 위하여 해 저 지층 탐사를 실시하였다. 이와 같이 수심 $60 \mathrm{~m}$ 급 정박지는 해 저 탐사를 통해 석션앵커의 설치 - 시공 측면에서 유리한 최적 위 치를 선정하고자 한다.

현재까지 해저 지층의 구조를 탐사하기 위한 방법으로 주로 탄성파 탐사를 이용해 왔다(Kearey and Brooks., 1991). 탄성파 탐 사 기법은 탐사할 지층의 깊이에 따라 주파수 대역을 구분하여 각기 다른 장비를 이용한다. 물속에서 압축공기를 터트리는 에 어건(Air gun)이나 중천부지층탐사기(Sparker)는 비교적 깊은 지 층 탐사에 사용되는 장비이며, 압전식 변환기(Piezoelectric transducer)를 진원으로 하여 음파를 발생시키는 천부지층탐사기 (Sub-bottom profiler, SBP)는 얕은 지층 탐사에 주로 사용된다. Lee et al.(2009)은 서해 경기만의 해저지층 구조와 퇴적 환경을 규명하고자 천부지층탐사기와 중천부지층탐사기를 이용한 탄성 파 탐사를 수행하여 음향상 분류를 통한 퇴적 환경 연구를 수행 한 바 있다. $\mathrm{Yu}(2010)$ 은 제주도 남부 해역에서 천부지층탐사기와 중천부지층탐사기를 이용하여 획득한 음향자료로부터 음향상 분류 및 퇴적 환경 분석을 수행하였다. Kim et al.(2016a)은 제주 도 차귀도 서북쪽 외해역에서 천부지층탐사기를 이용하여 탄성 파 탐사를 실시하였고, 퇴적물에 대한 성분 분석을 수행하였다. 지금까지 국내에서 이루어진 해저 지층 조사 연구에서는 단 순히 음향상 분류 또는 퇴적물 분석연구가 대부분이며, 파력발 전 실해역 시험장 선정과 같이 특별한 목적을 가지고 실시된 적은 없었다. 본 연구에서는 제주도 차귀도 북부 해역에 위치할 파력발전 실해역 시험장의 수심 $60 \mathrm{~m}$ 급 정박지로 적합한 최적의 위치를 찾기 위한 목적으로 탄성파 탐사를 통한 해저 지층 특 성 파악, 퇴적층의 깊이 분석을 수행하였다. 이를 위하여 천부 지층탐사기를 이용한 고주파 탄성파 탐사를 실시하여 퇴적층의 두께 분포를 파악하였다. 취득한 음향자료를 가지고 음향상 분 류 방법에 따라 해저 지층 형태의 특성을 파악하였고, 측면주사 음향측심기를 이용하여 해저면의 영상을 통해 해저 지형을 조
사하였다. 마지막으로 조사 해역 내의 여러 정점에서 시료 채취 기를 통해 얻은 퇴적물 시료에 대한 성분 분석을 통하여 표층 퇴적물의 물리적 특성을 파악하였다. 탐사 결과를 토대로 수심 $60 \mathrm{~m}$ 급 파력발전 실해역 시험장 정박지로써 조건에 부합하는 해 역을 최적 위치로 제안하였다.

\section{2. 재료 및 방법}

\section{1 탐사 해역 및 방법}

제주도 서부 및 차귀도 북부 해역을 포함하는 본 조사 해역의 수심은 약 $30 \sim 80 \mathrm{~m}$ 로, 제주도에서 멀어질수록 수심이 깊어지는 형태를 지니고 있다. 파력발전 실해역 시험장 수심 $60 \mathrm{~m}$ 급 정박 지를 선정하기 위하여 총 3차례 탐사를 실시하였다. Fig. 1은 각 탐사 영역과 탄성파 탐사 경로, 시료 채취 정점을 보여주고 있 다. 탐사는 제주대학교 해양조사선 제라호를 이용하여 2016년 5 월 31일(1차 탐사), 6월 1일(2차 탐사), 9월 22 23일(3차 탐사) 탐 사를 수행하였다. 해당 지역은 위도 $33^{\circ} 20.0000^{\prime} \mathrm{N} \sim 33^{\circ} 22.000$ $0^{\prime} \mathrm{N}$, 경도 $126^{\circ} 07.0000^{\prime} \mathrm{E} \sim 126^{\circ} 09.3000^{\prime} \mathrm{E}$ 에 위치한다. 1차 탐 사는 상대적으로 넓은 지역으로 위도와 경도 방향으로 $3.0 \mathrm{~km} \times$ $3.5 \mathrm{~km}$ 범위 내에서 탐사를 수행하였고(Fig. 1a), 1 차 탐사의 결과 를 토대로 조사범위를 좁혀 2차 탐사 $(1.75 \mathrm{~km} \times 2.0 \mathrm{~km})$ 을 실시하였 다(Fig. 1b). 마지막 3차 탐사 $(1.5 \mathrm{~km} \times 2.0 \mathrm{~km})$ 는 2 차 탐사와 조사지 역은 같지만 사선 방향으로 이동하면서 보다 세밀하게 조사하였 다.(Fig. 1b). 탄성파 탐사결과로부터 파악한 퇴적층 $10 \mathrm{~m}$ 이상인 해역에 속한 16 개 정점에서 시료 채취기를 이용하여 표층 퇴적 물을 취득하였다. 탐사 경로 상에 위치한 각 탐사별 실험 환경, 날짜, 사용 장비, 범위 그리고 각 차수별 탐사 경로와 경로별 거 리는 Table 1에 정리하였다.

\section{2 탐사 장비}

해저 지층 탐사는 Fig. 1에 나타난 탐사 경로를 따라 이동하 면서 데이터를 취득하였다. 1 3차 탐사 모두 천부지층탐사기를 사용하였고, 3 차 탐사에서만 추가적으로 시료 채취기와 측면주 사음향측심기를 사용하였다.

본 조사에서 사용된 탄성파 탐사 장비는 고주파 탐사 장비 중 하나인 천부지층탐사기(Teledyne Odom Hydrographic, Baton Rouge, Louisiana, USA)이다. 천부지층탐사기의 음원 신호는 $2 \sim 7 \mathrm{kHz}$ 의 주 파수 대역을 가진 주파수 변조(Frequency modulation, FM)를 통해 얻은 스윕 신호(Sweep signal)를 가진다. 중천부지층탐사기와 달리 높은 주파수 대역을 사용하기 때문에 해저 지층 내부로 깊은 곳까 지는 투과할 수 없지만, 분해능이 높아 정밀한 지층 조사가 가능하 다(Lee et al., 2009). 반사 신호에 정합 필터 기법을 사용하여 신호

Table 1 Specification of each survey regions and experimental equipments using the sub-bottom profiler (SBP), side scan sonar (SSS) and grab

\begin{tabular}{cccccccc}
\hline \hline \multirow{2}{*}{ Survey } & \multirow{2}{*}{ Date } & Equipments & Range $[\mathrm{km}]$ & \multicolumn{4}{c}{ Survey lines } \\
\cline { 5 - 8 } & & & & Latitude & Distance $[\mathrm{km}]$ & Longitude & Distance $[\mathrm{km}]$ \\
\hline $1^{\text {st }}$ & 2016. 05. 31 & SBP & $3.0 \times 3.5$ & $\mathrm{Z} 1 \sim \mathrm{Z} 8$ & 0.5 & $\mathrm{Y} 1 \sim \mathrm{Y} 5$ & $0.5 \sim 1.0$ \\
$2^{\text {nd }}$ & 2016. 06. 01 & SBP & $1.75 \times 2.0$ & $\mathrm{X} 1 \sim \mathrm{X} 9$ & 0.25 & $\mathrm{~V} 1 \sim \mathrm{V} 4$ & $0.25 \sim 1.0$ \\
$3^{\text {rd }}$ & 2016. 09. $22 \sim 23$ & SBP, SSS, Grab & $1.5 \times 2.0$ & & $01 \sim 13$ (Diagonal line) \\
\hline
\end{tabular}




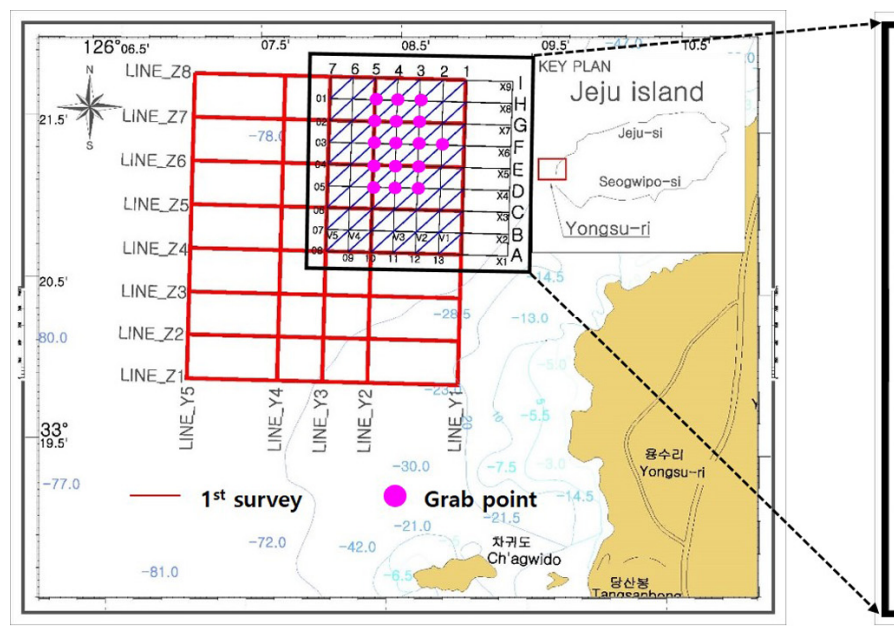

(a) $1^{\text {st }}$ survey lines and grab points

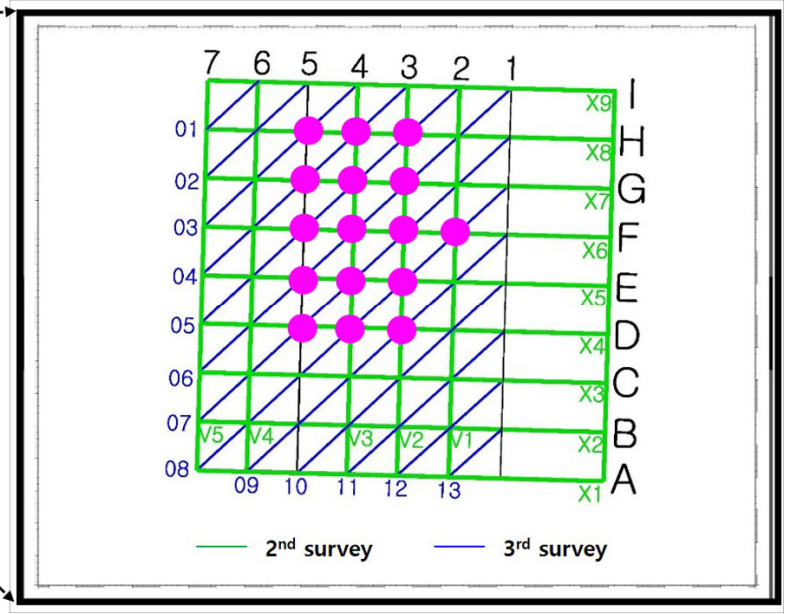

(b) $2^{\text {nd }}$ and $3^{\text {rd }}$ survey lines and grab points

Fig. 1 Location of the $1^{\text {st }} \sim 3^{\text {rd }}$ survey areas. Track lines(a, b) for seismic survey using a sub-bottom profiler (SBP) and 16 grab sampling points in the survey area

대 잡음비(Signal to noise ratio, SNR)를 향상시켜 고해상도 이미지 를 통해 퇴적층의 정밀한 구분이 가능하다(LeBlanc et al., 1992). 최대 출력을 사용하였으며 반복률(Rep. rate)은 $500 \mathrm{~ms}$ 로 설정하였 다. 수심에 따라서 펄스 길이(Pulse length)는 30 60ms로, 수신 이득 (Gain)은 6 30dB로 변경하면서 측정하였다. 또한 3 차 탐사에서 사 용한 탐사 장비는 측면주사음향측심기로, 음파가 해저 바닥에서 반사되어 오는 모양을 통해 해저면을 영상화 하는 장비로 측면주 사음향측심기이다. 이 장비는 해저 지형 분석 조사를 위해 주로 사용되며, 영상은 퇴적물의 평균 크기와 거칠기에 따라 변하는 음 향강도에 비례하여 다르게 나타난다(Kim et al., 2002; Lee et al., 2013). 사용 주파수는 $400 \mathrm{kHz}$ 고주파 대역으로, 촬영폭(Swath)은 $300 \mathrm{~m}$ 로 제한하여 천부지층탐사기와 동시에 조사선으로 예인하며 측정하였다. 마지막으로 해저면 퇴적물 시료는 탄성파 탐사를 통 해 획득한 음향상 분석을 수행한 후, 퇴적층이 $10 \mathrm{~m}$ 이상으로 나타 나는 해역을 대상으로 정점을 선정하고 시료 채취기 $(\mathrm{Grab})$ 를 이용 하여 획득하였다. 탐사 위치는 조사선에 설치되어 있는 DGPS (Differential global positioning system)을 이용하였으며, 항해 시 운 항 속도는 4 5knot(7.4 9.3km/h) 이내로 유지하였다.

\section{3. 분석 결과}

\section{1 음향상 분석 및 퇴적층 깊이 분석}

천부지층탐사기를 통해 획득한 탄성파 단면도의 정확한 분 류를 위해서 음향상 분류를 수행하였다. Chough et al.(2002)가 제안한 분류 방법을 일부분 수정하여 제시한 Kim et al.(2016a) 의 분류 방법에 따라 음향상을 세분화 하였다. Table 2 는 8 개 의 음향상 각각의 특징과 단면도를 보여주고 있다. 먼저 해저 면의 모양에 따라 각각 Type I(편평한 모양), Type II(둔덕 모 양) 그리고 Type III(불규칙한 모양)으로 크게 3종류로 구분하 였으며, 이를 다시 세분화하여 8개의 음향상으로 분류하였다. 수심 $60 \mathrm{~m}$ 급 정박지 조건에 부합되는 위치를 쉽게 찾기 위하여 암반 지역(빨강), $10 \mathrm{~m}$ 이내의 퇴적층(초록), $10 \mathrm{~m}$ 이상의 퇴적층 (파랑)으로 3 가지 색을 달리하여 Fig. 2의 탄성파 단면도 하부 에 나타냈다.

Fig. 2에는 각각의 탐사 경로 중 대표적인 탄성파 단면도를 나타내었다. 각 그림 상단에는 음향상 분류를 통해 분류된 음향 상을 표기하였다. 탄성파 단면도에서 볼 수 있는 해저 돌출 지

Table 2 Classification from each echo types of seismic images (Kim et al. 2016a)

$\begin{array}{lll}\text { Class } \quad \text { Type } & \text { Lescription drawing } \\ \text { II } & \text { I-1 } & \text { Lelatively flat seafloor with either no little sub-bottom reflectors } \\ \text { III } \quad \text { III-1 } & \text { III-2 }\end{array}$




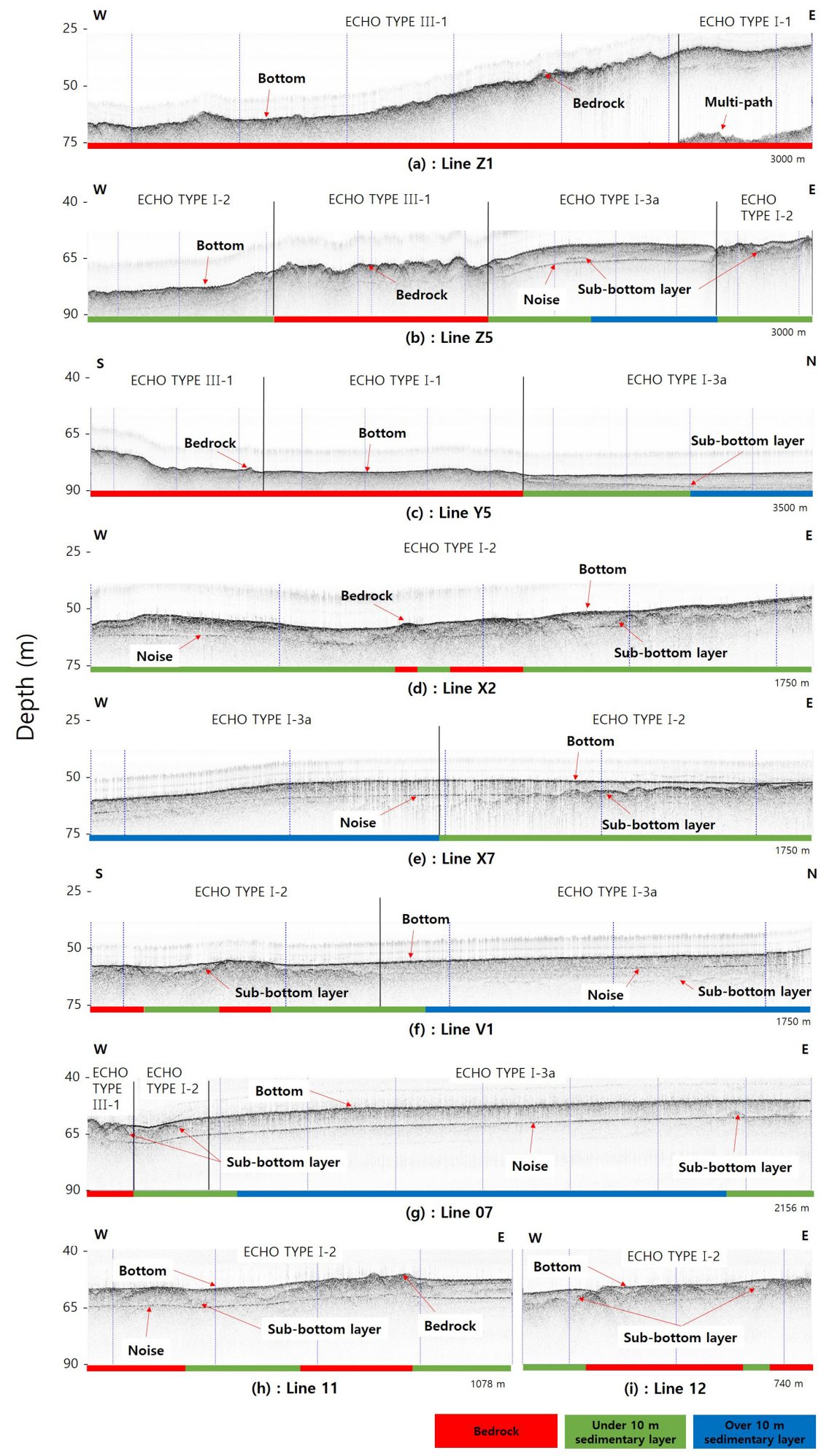

Fig. 2 Representative seismic images classified by echo type and sediment thickness

형은 기존 연구(Kim et al. 2016a)를 통해 암반(Bedrock)으로 판 단하였고, 모든 음향상에서 잡음(Noise) 라인이 나타남을 확인 하였다. Fig. 2a 오른쪽, Fig. 2c의 중앙 음향상에서 나타난 탄성 파 단면도는 해저면이 평탄하고 표면 반사가 뚜렷하여 내부 반 사층이 나타나지 않는 Type I-1 형태로 구분된다. Type I-1에 속 한 해저면은 주로 암반 지역이거나 조립질의 퇴적물이 표층에
두껍게 쌓여 있어 음파를 투과시키지 못한다(Damuth, 1980). Type I-2 형태는 내부 반사층이 나타나지 않는 Type I-1 형태와 다르게 불규칙으로 보이거나 부분적으로 끊겨서 나타난다. 부 분적으로 $10 \mathrm{~m}$ 이내의 퇴적층이 나타나며 일부 지역에서는 퇴적 층이 나타나지 않았다(Fig. $2 \mathrm{~b}, 2 \mathrm{~d}, 2 \mathrm{e}, 2 \mathrm{f}, 2 \mathrm{~g}, 2 \mathrm{~h}, 2 \mathrm{i}$ ). Type I-2에 속한 퇴적물은 Type I-1보다 비교적 크기가 작은 퇴적물이 분포 


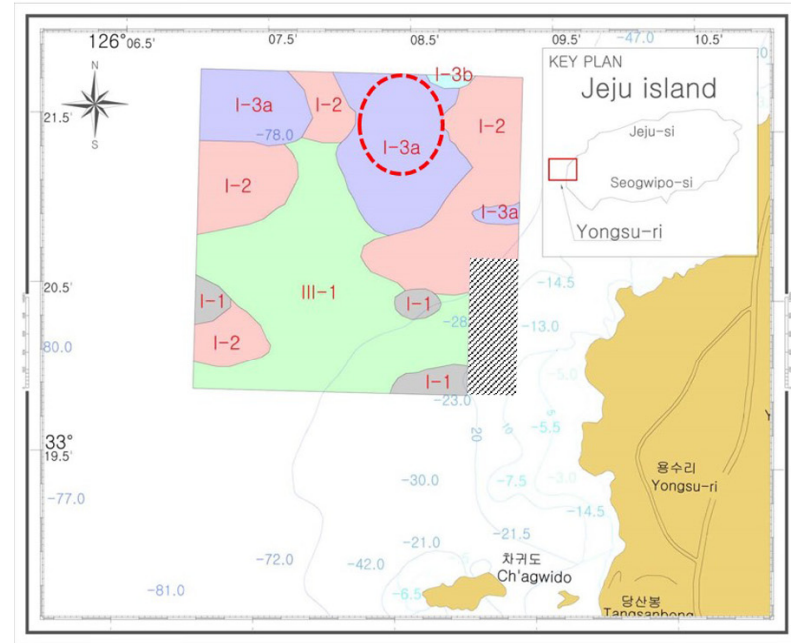

(a) Classified echo type

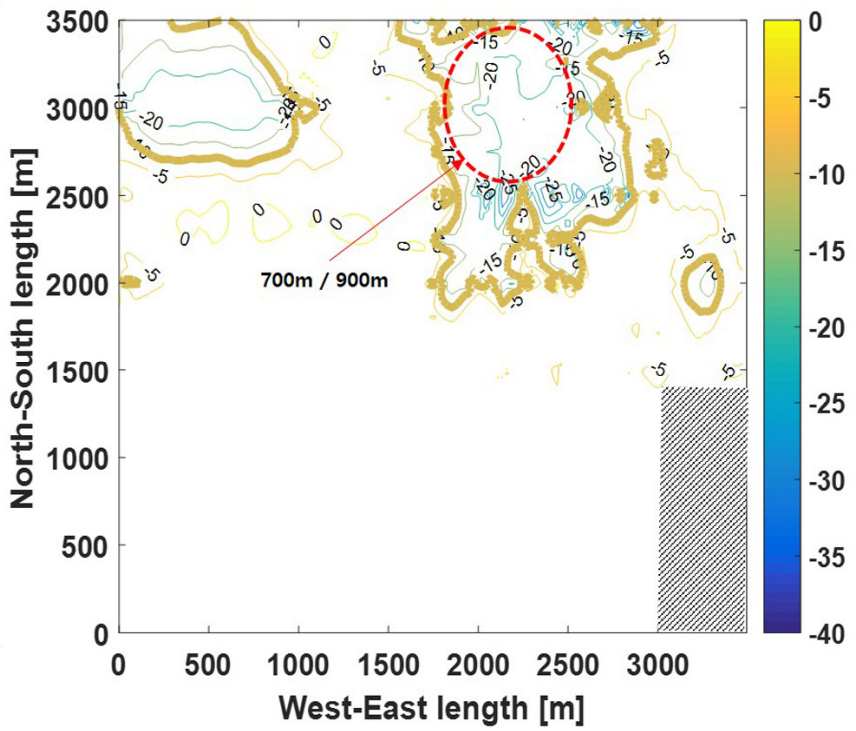

(b) Classified depth from sub-bottom layers

Fig. 3 (a) Classification of echo types in the survey area, and (b) contour of sediment thickness. The red dotted circles indicate the optimum location of the $60 \mathrm{~m}$-class sea test-bed

할 때 나타난다(Damuth, 1980). Type I-3은 해저면 표층이 주로 사질로 구성되어 있어 해저면의 첫 번째 층에서 상대적으로 큰 반사 신호가 나타나는 Type I-3a와 해저면 표층이 실트(Silt)와 점토(Clay) 비율이 높은 니사질 혹은 니질로 구성되어 있어 더 투명한 층으로 나타나는 Type I-3b로 구분할 수 있다. 본 조사 해역 내에서는 주로 북동부와 서북부 일부지역에서 Type I-3a가 나타남을 확인하였다(Fig. $2 \mathrm{~b}, 2 \mathrm{c}, 2 \mathrm{e}, 2 \mathrm{f}, 2 \mathrm{~g}$ ). Fig. $2 \mathrm{~b}, 2 \mathrm{c}$ 의 오른 쪽 일부분과, Fig. $2 \mathrm{e}$ 의 왼쪽, Fig. $2 \mathrm{f}$ 의 오른쪽 그리고 Fig. $2 \mathrm{~g}$ 의 중간 부분에서 $10 \mathrm{~m}$ 이상의 퇴적층이 나타남을 확인할 수 있다. $10 \mathrm{~m}$ 이상의 퇴적층을 확보한 해역에서는 주로 표층이 사질 혹 은 니사질의 세립토로 구성되어 있어 음파가 상대적으로 깊게 들어갈 수 있는 형태를 보인다(Kim et al., 2016a). 반면 Fig. 2a, $2 \mathrm{~b}, 2 \mathrm{c}$ 에서 부분적으로 보이는 해저면이 불규칙하고, 골 모양의 해저 지형을 가지며, 내부 반사층이 나타나지 않는 Type III-1에 서는 퇴적층이 없는 것으로 확인되었다. 이러한 지형은 조차가 큰 해역에 위치하여 수면 변동과 강 한 조류에 의한 비교적 소 규모 침식의 결과로 나타난다고 알려져 있다(Lee et al., 2009). 이 밖에도 둔덕 모양의 해저면 형태를 갖으며 내부 반사층이 나타나지 않는 Type II-1, 표층이 불규칙한 형태를 갖으며 주변 부에도 불규칙한 퇴적층이 나타나 변형된 둔덕 형태를 보이는 Type II-2, 해저면이 대규모 침식에 의하여 해저 지형의 변화가 매우 심한 형태를 보이는 Type III-2가 있다. 그러나 본 조사해 역 내에서 Type II-1, II-2, III-2의 음향상들은 나타나지 않았다.

1 3차 탄성파 탐사를 통하여 탐사 해역 내의 해저 지형 및 퇴 적층을 각각 음향상과 퇴적층 깊이별로 분류하였고, 그 결과를 종합하여 Fig. 3에 나타냈다. Fig. 3a에는 탐사 해역의 동남부, 서남부 등 일부지역에서는 Type I-1, 서부 및 동부 지역에서는 주로 Type I-2, 서북부, 북동부 지역에서는 Type I-3a, 북동부 일 부 지역에서는 Type I-3b 그리고 중앙 및 남부지역은 Type III-1 이 나타남을 확인하였다. Fig. $3 \mathrm{~b}$ 는 퇴적층 $10 \mathrm{~m}$ 영역을 찾기 위 하여 등고선 형태로 해저면 아래 퇴적층의 깊이를 나타내었다.
서북부와 북동부 지역에서 $10 \mathrm{~m}$ 이상의 퇴적층이 존재함을 확인 하였으나, 북동부 지역이 육지에서 가까우며 수심이 $50 \sim 70 \mathrm{~m}$ 이 내로 나타남을 확인하였다. 해당 해역은 석션 앵커 설치 조건에 맞는 수심 $60 \mathrm{~m}$ 급 정박지가 가능한 위치로 판단된다. 퇴적층 깊 이가 $10 \mathrm{~m}$ 이상으로 나타난 지역은 음향상 분류로 구분하였을 때 Type I-3a에 속한다.

동시에 3 차 탐사에서 운용한 측면주사음향측심기에서 각 탐 사 라인별 얻은 영상을 O et al.(2015)가 분석한 방법을 이용하 였다. 저장한 자료부터 KML(Keyhole markup anguage)파일을 생 성하여 모자이크 처리를 한 후, 하나의 이미지로 나타내었다 (Fig. 4) 취득한 영상을 분석 결과 전반적으로 3 차 탐사 영역내 의 서남쪽 또는 동남쪽 일부분 지역에서 암반이 노출된 것을 제외하곤 퇴적층이 고르게 분포하고 있음을 확인하였다.

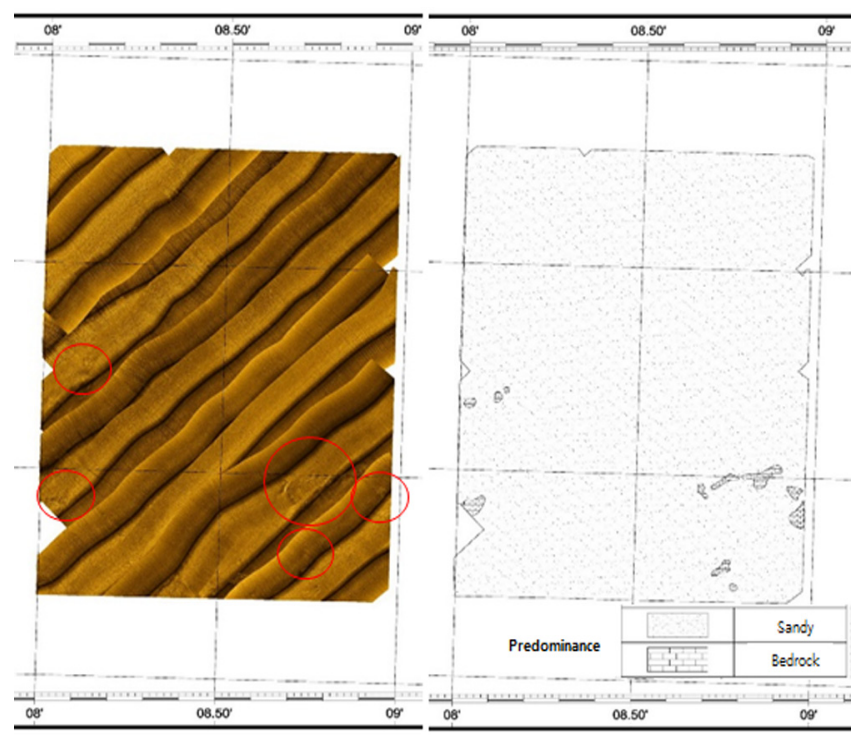

Fig. 4 Sonograph obtained from a side scan sonar (SSS) 
Table 3 Physical characteristics of sedimental samples at 16 locations

\begin{tabular}{|c|c|c|c|c|c|c|c|c|c|}
\hline \multirow[t]{2}{*}{ Point } & \multirow{2}{*}{$\begin{array}{l}\text { Specific weight } \\
{\left[\mathrm{g} / \mathrm{cm}^{3}\right]}\end{array}$} & \multirow{2}{*}{$\begin{array}{c}\text { Moisture } \\
\text { content }[\%]\end{array}$} & \multirow{2}{*}{$\begin{array}{l}\text { Specific } \\
\text { gravity }\end{array}$} & \multicolumn{3}{|c|}{ Composition [\%] } & \multicolumn{2}{|c|}{$\begin{array}{c}\text { Composition of only soil } \\
\text { particle [\%] }\end{array}$} & \multirow{2}{*}{$\begin{array}{l}\text { Unified soil } \\
\text { classification }\end{array}$} \\
\hline & & & & Sand & Silt & Organic & Sand & Silt & \\
\hline D3 & 1.69 & 29.34 & 2.720 & 78.4 & 12.0 & 9.6 & 86.7 & 13.3 & SP-SM \\
\hline D4 & 1.49 & 29.54 & 2.603 & 69.7 & 12.5 & 17.8 & 84.8 & 15.2 & SM \\
\hline D5 & 1.68 & 34.17 & 2.581 & 32.9 & 9.4 & 57.7 & 77.7 & 22.3 & SP-SM \\
\hline E3 & 1.70 & 31.54 & 2.632 & 73.0 & 12.2 & 14.8 & 85.2 & 14.8 & SM \\
\hline $\mathrm{E} 4$ & 1.71 & 27.22 & 2.653 & 64.6 & 13.1 & 22.2 & 83.1 & 16.9 & SM \\
\hline E5 & 1.66 & 35.55 & 2.647 & 46.6 & 16.8 & 36.5 & 73.5 & 26.5 & SM \\
\hline $\mathrm{F} 2$ & 1.66 & 30.49 & 2.576 & 70.9 & 14.6 & 14.5 & 82.9 & 17.1 & SM \\
\hline F3 & 1.76 & 29.75 & 2.646 & 65.6 & 16.3 & 18.0 & 80.1 & 19.9 & SM \\
\hline $\mathrm{F} 4$ & 1.70 & 38.84 & 2.603 & 59.1 & 15.9 & 25.0 & 78.8 & 21.2 & $\mathrm{SM}$ \\
\hline F5 & 1.75 & 30.62 & 2.609 & 62.0 & 11.9 & 26.1 & 83.9 & 16.1 & SP-SM \\
\hline G3 & 1.67 & 32.79 & 2.636 & 64.0 & 19.1 & 16.9 & 77.0 & 23.0 & SM \\
\hline G4 & 1.65 & 33.86 & 2.563 & 56.9 & 18.4 & 24.7 & 75.6 & 24.4 & SM \\
\hline G5 & 1.74 & 29.65 & 2.604 & 58.2 & 11.8 & 29.9 & 83.1 & 16.9 & SP-SM \\
\hline $\mathrm{H} 3$ & 1.71 & 32.70 & 2.715 & 61.7 & 12.9 & 25.4 & 82.8 & 17.2 & $\mathrm{SM}$ \\
\hline $\mathrm{H} 4$ & 1.71 & 30.76 & 2.615 & 58.0 & 19.0 & 23.0 & 75.3 & 24.7 & $\mathrm{SM}$ \\
\hline H5 & 1.63 & 38.71 & 2.699 & 37.5 & 11.6 & 50.9 & 76.4 & 23.6 & SP-SM \\
\hline
\end{tabular}

\section{2 퇴적물 시료 분석}

퇴적물 시료 분석은 주로 시료의 물리적, 역학적 특성을 파악 하여 시료의 상태나 기본적인 성질 파악, 기본 물성치 간의 상관 성 분석에 있어서 중요한 자료로 활용된다(Das, 1990). 탄성파 단 면도의 분석 자료를 통하여 수심 $60 \mathrm{~m}$ 급 정박지로써 적절하다고 판단되는 퇴적층 $10 \mathrm{~m}$ 이상인 해역 내 16 개 대표 정점에서 해저 면 표층 시료를 채취하여 시료 분석 시험을 실시하였다(Fig. $1 \mathrm{~b}$ 참조). 본 연구에서는 각 정점별 퇴적물 시료의 구성 비율, 비중 량, 함수율, 비중 시험, 통일 분류법을 이용한 분류를 실시하였고, 시료 분석 시험을 통하여 얻은 결과는 Table 3 에 정리하였다. 먼 저 비중량(Specific weight)은 시료가 습윤 상태로 있을 때 단위 부 피당 중량을 측정하는 방법이고, 함수비(Moisture content)는 시료 에 포함되어 있는 물의 양을 나타내는 척도이며, 비중(Specific gravity)은 시료의 공기 중 무게와 부력의 비로 각 정점별로 3 번의 실험을 실시하여 그 평균값을 나타내었다. 정점에 따라 약간씩 다르지만 습윤 단위 중량은 $1.49 ~ 1.76 \mathrm{~g} / \mathrm{cm}^{3}$ 이내로 나타났으며, 함수비는 $\mathrm{F} 4, \mathrm{H} 5$ 정점에서만 가장 높은 $38 \%$ 로 측정되었고 나머 지 정점에서는 29 35\% 정도로 나타났다. 비중은 유기물을 제거 한 시료에 대해서 측정한 결과, 정점별로 큰 차이가 없는 약 2.56 2.72 이내의 값으로 나타났다.

입도 분석 실험 결과, 시료 전체에서 모래 입자가 차지하는 비율은 유기물을 포함하면 38 78\%, 유기물을 제외하면 75 86\% 로 나타났으며, 유기물의 함유 비율은 D5와 H5 시료에서 $50 \%$ 이상 포함된 것을 확인할 수 있었다. 반면 유기물을 제거한 순 수한 퇴적물 시료의 입자만으로 분석한 결과, 모든 정점에서 실 트의 비율이 13 26\% 이내로 나타남을 확인하였다. 마지막으로 통일 분류법(Unified soil classification system, USCS)에 따라 시 료를 분류하였다(Robert, 1980). 분류 방법은 No. 4체(4.75mm)와
No. 200 체 $(75 \mu \mathrm{m})$ 를 통과하는 비율을 가지고 $50 \%$ 미만이면 조립 토, 이상이면 세립토로 구분한다. 입도 분포가 불량한 모래(Sand poorly-graded, SP), 입도 분포가 양호하고 실트가 섞인 모래 (Sandy silt SM) 그리고 두 개가 혼합되어 나타나는 입도가 나쁜 실트질 모래(SP-SM)로 구분할 수 있다. $\mathrm{SP}$ 는 세립토의 함량이 $5 \%$ 미만이고, SP-SM은 5 12\% 그리고 SM은 $12 \%$ 이상이다. 본 탐사 해역에서 채취한 시료를 둘로 나눠 반은 물로 세척하여 유기물을 제거한 상태로 분석하였고, 나머지는 반은 유기물을 포함한 상태로 분석하였다. 그 결과, 본 해역에서 나타난 성분 은 주로 모래 성분으로 구성 되어 있음을 확인하였다. 유기물을 제거한 시료에 대하여 모든 정점에서 $\mathrm{SM}$ 으로 분류되었고, 유기 물을 포함하면 SP-SM이 D3, D5, F5, G5, H5 정점에서 나타남을 확인하였다.

\section{4. 결 론}

본 연구에서는 제주도 차귀도 파력발전 실해역 시험장의 수 심 $60 \mathrm{~m}$ 급 정박지로써 제시된 네 가지 조건을 만족하는 적절한 해역을 제안하는데 목적이 있다. 해저 지층 탐사를 위해 천부지 층탐사기를 이용하여 조사 해역 내에서 3차례 탐사를 수행하였 고, 일부 탐사에서는 측면주사음향측심기를 이용하여 해저면 영상을 통해 해저 지형을 분석하였다. 천부지층탐사기를 통해 획득한 자료는 Kim et al.(2016a)가 제안한 음향상 분류 방법에 따라 분류하였다. 음향상 분류 결과 조사 해역 내의 동남쪽과 서남쪽의 일부지역에서는 편평한 모양(Type I-1)이, 서쪽 및 동 쪽에서는 둔덕 모양(Type I-2)이, 서북쪽과 북동쪽에서는 편평한 모양 중 주로 사질로 구성되어 있는(Type I-3a)이 중앙부에서는 주로 불규칙한 모양(Type III-1)으로 확인하였다. 측면주사음향 
측심기를 통해 해저면 영상 분석 결과 서남쪽과 동남쪽 일부에 서 노출된 암반이 나타남을 확인하였다. 퇴적층 깊이 분석 결과 를 통해 서북쪽과 북동쪽 일부 지역에서 $10 \mathrm{~m}$ 이상의 퇴적층이 비교적 넓게 분포함을 확인하였다. 조사 해역 내에서 해상 변전 시설과의 근접한 위치를 고려하면, 북동쪽 해역이 수심 $60 \mathrm{~m}$ 급 정박지 조건에 가장 적합할 것으로 판단된다.

천부지층탐사기를 운용할 때 고정된 수층 음속 값 $(1500 \mathrm{~m} / \mathrm{s})$ 를 사용하였으며, 하부 지층의 음속은 고려하지 않았기 때문에 실제로는 퇴적층의 두께가 다를 것으로 예측된다. 비교적 평탄 하고 넓은 지역을 선정조건으로 두어 수심 변화 및 해저 지형 물로 인한 파랑의 굴절 및 회절과 같은 파랑 변형이 적게 발생 할 것이며, 정확한 파력발전장치 성능평가에 이점으로 작용할 것으로 사료된다. 이와 같이 석션 앵커의 설치 및 시공에 유용 한 조건을 기준으로 조사 해역 내 최적 위치를 수심 $60 \mathrm{~m}$ 급 정 박지로 제안하였다. 마지막으로 퇴적층 $10 \mathrm{~m}$ 이상의 해역 내 임 의의 16 개의 정점에 대하여 퇴적물 시료를 분석한 결과, 주로 세립토의 모래 혹은 실트가 섞인 모래가 존재함을 확인하였다. 본 시료 특성 값들은 퇴적물의 역학적 성질을 알 수 있는 중요 한 자료로 추후 석션 앵커를 설계할 때 활용될 것이다.

\section{후 기}

본 연구는 해양수산부의 해양청정에너지기술개발사업 “파력 발전 실해역 시험장 구축”과제의 지원으로 수행되었으며, 연구 비 지원에 감사드립니다.

\section{References}

Chough, S.K., Kim, J.W., Lee, S.H., Shinn, Y.J., Jin, J.H., Suh, M.C., Lee, J.S., 2002. High-resolution Acoustic Characteristics of Epocontinental Sea Deposits, Central-eastern Yellow Sea. Marine Geology, 188, 317-331.

Damuth J.E., 1980. Use of High-frequency (3.5 12 kHz) Echograms in the Study of Near-bottom Sedimentation Processes in the Deepsea: a Review. Marine Geology, 24, 73-95.

Das, B.M., 1990. Principles of Geotechnical Engineering. $2^{\text {nd }}$ Edition, PWS-KENT Publishing Company, Boston. USA

Kearey, P., Brooks, M., 1991. An Introduction to Geophysical Exploration. Second Edition. Blackwell Scientific Publications, USA, 254.

Kim, H.S., Hyeon, J.W, Jin, C.J, Kim, J.R., Cho, I.H., 2016a. Survey of Sedimentary Environment and Sediment at the West-Northern Site of Chagwi-do nearby Jeju Island. Journal of Korean Society Marine Environment and Energy, 19(2), 137-143.

Kim, K.O., Kim, Y.S., Kim, T.H., Ko, B.H., 2005a. Centrifuge Model Test on the Pullout Capacity of Embedded Suction Anchor with Flanges in Sand Layer. Proceedings of Korean Society of Civil Engineers Conference, Korean Society of Civil Engineers, 3427-3430.

Kim, K.O., Kim, Y.S., Ko, B.H. 2005b. Centrifuge Model Tests on the Pullout Capacity of Embedded Suction Anchor without Flanges in Sand Layer. 2005 Joint Conference of Geotechnical Engineering, Korean Society of Civil Engineers, 517-520.

Kim, S.R., Woo, H.J., Lee, Y.K., Jeong, K.S., Je, J.G., Park, G.T., Jung, B.H., Cho, J.H., 2002. Sea-bottom Sediments and Seafloor Acoustic Image by Side Scan Sonar on Sindu-ri Offshore. Journal of the Korean Earth Science Society, 23, 707-721.

Kim, Y.D., Hong K., Shin S.H., Kim K., Lim C.H., Ko T.K., Lee K., Park J.Y., Kim J.S., Choen H.J., Cho I.H., Bae Y.H., Choi J.S., 2016b. Estiablishment Plan of Open Sea Test Bed for Wave Energfy Converters. Proceeding of The Korean Society For New And Renewable Energy, 144.

LeBlanc, L.R., Mayer, L., Rufino, M., Schock, S.,G., King, J., 1992. Marine Sediment Classification using the Chirp Sonar. Journal of the Acoustic Society of America 91, 107-115.

Lee, C.K., Jung, S.K., Kim, S.R., 2013. Distribution of Flood Sediment Deposits using the Seafloor Image by Side Scan Sonar near the Northern Coast of Gungchon-ri, East Sea. Journal of Korean Earth Science Society, 34(1), 41-50.

Lee, G.S., Kim, D.C., Seo, Y.K., Yi, H.I., Yoo, S., 2009. Sedimentary Environment and Sequence Study Using High Resolution Seismic Survey in Gyunggi Bay, the Yellow Sea. Korean Journal of Fisheries and Aquatic Sciences, 42(6), 683-694.

O, H.S., Kim, T.H., Kwon, S.D., Kim, S.R., Shin, S.I., Kim, S.J., Kim, S.Y., Woo, J.S., 2015. Applications of Side Scan Sonar for Shipbuilding and Offshore Project. Journal of Ocean Engineering and Technology, 29(5), 373-379.

Robert, L.F., 1980. Petrology of Sedimentary Rocks. $2^{\text {nd }}$ Edition, Hemphill Publishing Company, CA, USA.

Yu, S., 2010. High Resolution Seismic Study on Sedimentary Structure in the Southern Shelf of Jeju Island. Thesis of the Graduate School of Pukyung University, 1-11. 